\title{
KETERKAITAN KARAKTERISTIK HABITAT DENGAN KEPADATAN KEPITING BAKAU PADA EKOSISTEM MANGROVE DESA EVU KECAMATAN HOAT SOARBAY KABUPATEN MALUKU TENGGARA
}

\author{
(The Relationship of Habitat Characteristics With The Density of Mud Crabs \\ on Mangrove Ecosystem of Evu Village \\ Hoat Soarbay District Southeast Maluku Regency)
}

\author{
Muhammad Yunus ${ }^{1}$ dan Laura Siahainenia ${ }^{2 *}$ \\ ${ }^{1)}$ Mahasiswa Program Studi Magister Ilmu Kelautan Pascasarjana Universitas Pattimura \\ biologilaut2016@gmail.com \\ ${ }^{2)}$ Jurusan Manajemen Sumberdaya Perairan Fakultas Perikanan dan Ilmu Kelautan Universitas Pattimura \\ *laura.siahainenia@gmail.com \\ Corresponding author*
}

\begin{abstract}
ABSTRAK: Penelitian dilakukan di ekosistem mangrove Desa Evu Kecamatan Hoat Soarbay Kabupaten Maluku Tenggara, sejak Maret-Mei 2018. Penelitian bertujuan menganalisis keterkaitan karakteristik habitat dengan kepadatan kepiting bakau pada ekosistem mangrove Desa Evu. Analisis karakteristik habitat meliputi parameter suhu, salinitas, $\mathrm{pH}, \mathrm{DO}$, kerapatan mangrove dan presentasi fraksi substrat. Sampling kepiting bakau untuk menganalisis kepadatan menggunakan metode proporsive sampling pada 9 (Sembilan) stasiun dengan karakter habitat yang berbeda. Analisis keterkaitan kepadatan kepiting bakau pada tiap stasiun menggunakan metode Analisis Komponen Utama (Principal Component Analysis). Secara umum nilai parameter fisik, kimiawi dan biologis ekosistem mangrove Desa Evu masih dalam kondisi baik dan dapat ditolelir oleh kepiting bakau. Kepadatan kepiting bakau pada ekosistem mangrove Desa Evu tergolong tinggi, baik berdasarkan spesies maupun jenis kelamin. Scylla olivacea berdistribusi tinggi zona yang ditumbuhi mangrove mangrove Xylocarpus sp. Rhizophora mucronata dan Bruguiera sp. dengan nilai $\mathrm{pH}$, DO, dan salinitas yang tinggi; serta fraksi substrat pasir halus dan pasir kasar. Sedangkan S. serrata berdistribusi tinggi zona yang ditumbuhi mangrove Sonneratia alba, Rhizophora mucronata dan Bruguiera sp., serta bersubstrat dasar pasir halus dan lumpur.
\end{abstract}

Kata Kunci: Scylla serrata, mangrove, kepadatan, Hoat Soarbay, Evu.

ABSTRACT: The study was conducted in the mangrove ecosystem of Evu Village, Hoat Soarbay District, Southeast Maluku Regency, from March to May 2018. The study aimed to analyze the relation of habitat characteristics with the density of the mud crabs. Analysis of habitat characteristics includes parameters of temperature, salinity, $\mathrm{pH}, \mathrm{DO}$, mangrove density and substrate. Mangrove crab sampling using proporsive sampling method at nine stations with different characteristics. The relation of the mud crabs density and its habitat characteristics using the Principal Component Analysis method. In general, the physical, chemical and biological parameters of the mangrove ecosystem of Evu Village are still in good condition and can be tolerated by mud crabs. The density of mud crabs in mangrove ecosystem is relatively high. Scylla olivacea was highly distributed at zones with Xylocarpus sp. Rhizophora mucronata and Bruguiera sp.; high $\mathrm{pH}$, DO, and salinity values; and fine sand and coarse sand of substrate stucture. Whereas S. serrata was highly distributed at 
DOI: https://doi.org/10.30598/TRITONvol15issue2page58-68

zones with Sonneratia alba, Rhizophora mucronata and Bruguiera sp., and fine sand and mud as substrate structure.

Keywords: Scylla serrata, mangrove, density, Hoat Soarbay, Evu.

\section{PENDAHULUAN}

Ekosistem mangrove adalah ekosistem yang terdapat pada zona intertidal yang merupakan peralihan antara darat dan laut. Ekosistem mangrove terdistribusi luas di wilayah perairan tropis dan subtropis, menempati area sepanjang pantai semi-tertutup dan muara sungai. Ekosistem mangrove memberikan manfaat ekologis yang sangat besar bagi ekosistem di sekitarnya secara langsung maupun tidak langsung. Ekosistem mangrove merupakan pelindung ekosistem daratan dari hantaman ombak dan gelombang besar, menjaga eksistensi garis pantai dan tebing sungai dari dampak erosi dan abrasi, serta melindungi ekosistem laut (lamun dan terumbu karang) dari kelebihan pasokan sedimen dan unsur hara daratan, serta limpasan air tawar. Ekosistem mangrove merupakan ekosistem yang subur karena mampu memerangkap air, sedimen, dan menghasilkan detritus, serta merupakan habitat ideal bagi berbagai mikroorganisme yang merupakan komponen dasar rantai makanan (Behera et al., 2014). Dengan demikian, ekosistem mangrove memberikan daya dukung yang besar bagi berbagai organisme darat maupun laut yang menjadikan ekosistem ini sebagai tempat berlindung, mencari makan, dan berkembang biak (Siahainenia et al., 2016). Salah satu organisme khas ekosistem mangrove yang memanfaatkan ekosistem mangrove sebagai habitat alami utama adalah kepiting bakau (Scylla spp.). Kepiting bakau tergolong dalam subfilum Crustacea dari kelas Dekapoda.

Distribusi spasial kepiting bakau pada ekosistem mangrove, terjadi sebagai akibat adanya preferensi dari tiap spesies kepiting bakau, karena tingkat adaptasi yang berbeda terhadap dinamika perubahan lingkungan (Siahainenia, 2010). Distribusi kepiting bakau di ekosistem mangrove memiliki keterkaitan erat dengan karakteristik habitat yang sesuai (Avianto, 2013). Pada awal daur hidup, embrio kepiting bakau dipijahkan, diinkubasi dan ditetaskan pada perairan laut, dan seiring pertumbuhan dan perkembangannya, megalopa kepiting bakau memasuki ekosistem mangrove melalui muara sungai. Selanjutnya setelah mencapai dewasa, kepiting bakau yang mengandung massa telur akan bermigrasi ke laut untuk menijah. Dengan demikian terjadi fenomena biologis yang unik dalam daur hidup kepiting bakau kepiting bakau yaitu migrasi reproduksi. (Siahainenia et al., 2016). Fenomena tersebut menyebabkan adanya distribusi spasial kepiting bakau pada ekosistem mangrove baik menurut spesies, jenis kelamin, dan tingkat kedewasaan.

Kepiting bakau merupakan komoditi perikanan penting di Indonesia, yang bernilai ekonomis tinggi (Larosa et al., 2013) dan sangat diminati konsumen. Selain memiliki rasa yang lezat, nilai gizi daging kepiting bakau juga tinggi. Dengan demikian komoditi kepiting bakau dapat dijadikan bahan pangan berpotensi. Menurut Karim (2005) dalam Katandagho (2014), daging kepiting bakau mengandung $47.5 \%$ protein dan $11.20 \%$ lemak. Selain itu juga terdapat kandungan EPA dan DHA, serta mineral $\mathrm{Na}, \mathrm{K}, \mathrm{Ca}, \mathrm{Mg}, \mathrm{Fe}, \mathrm{Zn}, \mathrm{Se}$ (Sundarrao et al., 2004 dalam Katiandagho, 2014). Sebagai komoditi bernilai ekonomis, permintaan kepiting bakau dari tahun ke tahun semakin meningkat. Padahal pemenuhan permintaan konsumen masih dipasok melalui penangkapan di alam sebesar $61,6 \%$, sedangkan sisanya dari hasil budidaya pembesaran. Kondisi ini terjadi akibat keterbatasan sistem dan teknologi budidaya untuk menghasilkan benih secara massal, serta penanganan pasca pembenihan (Yamin dan Sulaeman, 2011).

Peningkatan permintaan terhadap komoditi kepiting bakau menyebabkan 
intensitas penangkapan nelayan semakin tinggi pula. Disisi lain, eksistensi ekosistem mangrove sebagai habitat alami utama kepiting bakau semakin terancam akibat konflik pemanfaatan lahan pesisir (Siahainenia, 2014). Kondisi ini terjadi dihampir semua ekosistem mangrove di Indonesia, termasuk ekosistem mangrove Desa Evu Maluku Tenggara yang memiliki luas kurang lebih 959,05 hektar. Kawasan ini merupakan salah satu kawasan konservasi pesisir dan pulau-pulau kecil (KKP3K) di Maluku Tenggara, namun seiring peningkatan jumlah penduduk, aktivitas pemanfataan ekosistem mangrove Desa Evu semakin meningkat, termasuk aktivitas penangkapan dan pengumpulan sumberdaya hayati. Salah satu sumberdaya hayati yang menjadi target eksploitasi nelayan yaitu kepiting bakau, dengan tujuan konsumsi, dan perdagangan tingkat lokal, nasional maupun ekspor. Menurut Tetelepta dan Makatita (2012), jika kondisi ini berlangsung terus-menerus tanpa pengawasan dan pengaturan pemanfaatan yang tepat maka dikuatirkan terjadi penangkapan berlebih sehingga menyebabkan penurunan stok alami. Hasil observasi di ekosistem Pelita Jaya, Seram Barat Maluku, telah terjadi penurunan jumlah populasi dan ukuran individu kepiting bakau. Sebagai upaya pencegahan penurunan produksi alamiah kepiting bakau baik baik secara kualitas maupun kuantitas, maka perlu dirumuskan strategi pengelolaan sumberdaya kepiting bakau dan habitatnya. Rumusan strategi pengelolaan harus didasarkan pada data dan informasi hasil kajian pada ekosistem mangrove Desa Evu, sehingga tepat sasaran. Sebenarnya Ancaman terhadap keberadaan populasi kepiting dan habitatnya telah diantisipasi Pemerintah. melalui Peraturan Menteri Kelautan dan Perikanan Republik Indonesia No 56 Tahun 2016 tentang pembatasan perdagangan sumberdaya crustacea (termasuk kepiting bakau). Namun regulasi tersebut belum menjamin pemanfaatan berlebih. Hasil observasi menunjukan nelayan setempat masih menangkap kepiting bakau dengan diluar kriteria yang disyaratkan aturan dimaksud. Dengan demikian perlu dilakukan kajian-kajian untuk mengumpulkan data dan informasi pendukung rumusan strategi pengelolaan sumberdaya kepiting bakau dan habitatnya. Salah satu informasi penting yaitu keterkaitan karakteristik habitat dan kepadatan kepiting bakau. Penelitian ini bertujuan untuk menganalisis keterkaitan karakteristik habitat dengan kepadatan kepiting bakau pada ekosistem mangrove Desa Evu.

\section{METODE PENELITIAN}

Penelitian ini dilaksanakan pada bulan MaretMei 2018 di 9 (sembilan) stasiun penelitian di ekosistem mangrove Desa Evu, Kecamatan Hoat Soarbay Kabupaten Maluku Tenggara (Gambar 1). Alat dan bahan yang digunakan yaitu GPS, water quality checker (multi 3430 SET F), sediment core, automatic seaving shaker, meter roll, tabel pasang surut, timbangan digital, tali, alat tangkap kepiting (bubu \& gancu), buku pedoman identifikasi spesies kepiting bakau, alat tulis menulis dan daging ikan sebagai umpan.

\section{Karakteristik Habitat}

Pengukuran parameter fisik dan kimia berupa suhu, salinitas, $\mathrm{pH}$, DO, dan fraksi substrat dilakukan untuk mengetahui karakter habitat kepiting bakau tiap stasiun. Pengukuran dilakukan pada tiap stasiun secara acak dengan pengulangan. Parameter biologis yang diambil meliputi data vegetasi mangrove, yang dikumpulkan menggunakan metode transect line plots (Khouw. 2016), dengan prosedur sebagai berikut :

1. Pada sepanjang garis transek, dibuat petak pengamatan berukuran 10 x $10 \mathrm{~m}$ untuk kategori pohon (diameter $>10 \mathrm{~cm}$ ).

2. Vegetasi mangrove pada tiap petak pengamatan diidentifikasi dan dihitung jumlah tegakan tiap spesies.

Sampling kepiting bakau dilakukan dengan prosedur sebagai berikut:

1. Pada tiap substasiun penelitian, ditandai areal seluas $10 \times 10 \mathrm{~m}$. pada areal tersebut, ditempatkan bubu berdimensi $110 \times 70$ × 50 cm secara acak. 
DOI: https://doi.org/10.30598/TRITONvol15issue2page58-68

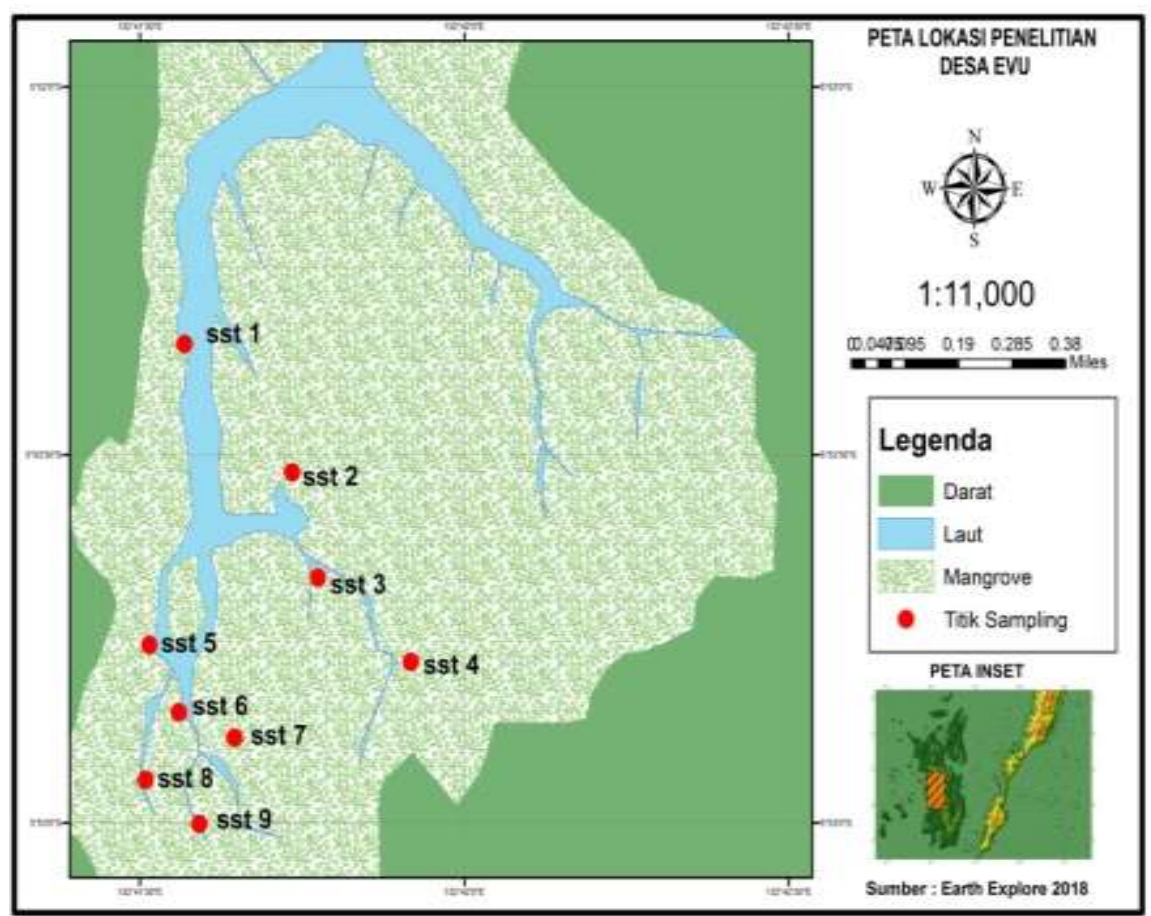

Gambar 1. Peta Lokasi Penelitian

2. Pada tiap substasiun penelitian, ditandai areal seluas $10 \times 10 \mathrm{~m}$. pada areal tersebut, ditempatkan bubu berdimensi $110 \times 70 \times 50$ $\mathrm{cm}$ secara acak.

3. Penangkapan dengan bubu dilakukan selama sehari.

4. Perangkap (bubu) pada tiap petak pengamatan selalu berubah setiap kali pengulangan, sehingga diharapkan dapat mewakili keseluruhan luasan petak pengamatan.

\section{Metode Analisis Data}

Analisis kerapatan vegetasi mangrove menggunakan rumus menurut Bengen (2000):

- Kerapataan jenis (ind)

$$
\mathrm{K}=\frac{\text { jumlah individu satu jenis }}{\text { luas petak contoh }}
$$

- $\quad$ Kerapatan relatif $(\mathrm{KR})(\%)$

$$
\mathrm{KR}=\frac{\text { kerapatan satu jenis }}{\text { Kerapatan semua jenis }} \times 100 \%
$$

- Presentasi fraksi substrat menggunakan rumus:

$$
\text { Persentasi butiran partikel }(\%)=\frac{\text { berat tiap ukuran sedimen }(g r)}{\text { berat total populasi sedimen }} \times 100
$$

- Kepadatan kepiting bakau dihitung dengan menggunakan rumus:

$$
D i=\frac{N i}{A}
$$

Keterangan :

Di =Kepadatan jenis ke-i $\left(100 \mathrm{~m}^{2}\right)$

$\mathrm{Ni}=$ Total individu jenis ke-i yang ditemukan

$\mathrm{A}=$ Luas area pengambilan $\left(100 \mathrm{~m}^{2}\right)$

Analisis keterkaitan karakteristik habitat dengan kepadatan kepiting bakau menggunakan metode analisis komponen utama (Principal Component Analysis), sebagai metoda statistik deskriptif multivariabel yang mempresentasikan informasi maksimum dari suatu matriks data ke dalam bentuk grafik informasi. Hasil analisis komponen utama menunjukan korelasi antar karakteristik habitat dan kepadatan kepiting bakau pada setiap stasiun selama fase bulan pengamatan. 


\section{HASIL DAN PEMBAHASAN}

\section{Karakteristik Habitat Parameter Suhu, Salinitas, pH dan DO}

Hasil pengukuran menunjukan suhu perairan pada ekosistem mangrove Desa Evu berkisar antara $27,36-29,22^{\circ} \mathrm{C}$ (Tabel 1). Suhu perairan sangat berpengaruh terhadap aktivitas kepiting bakau. Nilai suhu yang tinggi dapat meningkatkan laju metabolisme dan aktifitas pergerakan, serta laju perkembangan dan pertumbuhan embrio, pertumbuhan dan reproduksi (Siahainenia et al,. 2016). Menurut Shelley dan Lovatelli (2011) kepiting bakau dapat hidup pada perairan dengan kisaran suhu 25-35 ${ }^{\circ} \mathrm{C}$, sementara Cholik (1999) menyatakan kisaran suhu optimum bagi pertumbuhan kepiting bakau $28-33^{\circ} \mathrm{C}$. Dikatakan juga bahwa apabila suhu air turun di bawah nilai $20^{\circ} \mathrm{C}$ maka pertumbuhan kepiting bakau akan menjadi lebih lambat. Larva $S$. serrata menjadi lebih cepat tingkat pertumbuhannya apabila berada pada perairan dengan kisaran suhu $28-30^{\circ} \mathrm{C}$ (Ruscoe et al., 2004). Mawarni et al. (2014) menyatakan bahwa kepiting bakau menyebar secara baik pada pada perairan dengan kisaran suhu 21$33^{\circ} \mathrm{C}$. Dengan demikian kisaran nilai suhu pada ekosistem mangrove Desa Evu berada pada kisaran nilai suhu yang dapat ditolelir dan menunjang pertumbuhan kepiting bakau.

Tabel 1. Kisaran Nilai Suhu, Salinitas, pH dan DO Perairan Ekosistem Mangrove Desa Evu.

\begin{tabular}{clc}
\hline No & \multicolumn{1}{c}{ Parameter } & Kisaran Nilai \\
\hline 1 & Suhu $\left({ }^{\circ} \mathrm{C}\right)$ & $27.36-29.22$ \\
2 & Salinitas $(\mathrm{ppt})$ & $12.58-22.13$ \\
3 & $\mathrm{pH}$ & $7.48-7.80$ \\
4 & DO $(\mathrm{mg} / \mathrm{l})$ & $1,74-4,35$ \\
\hline
\end{tabular}

Nilai salinitas perairan pada ekosistem mangrove Desa Evu yang terukur selama penelitian berlangsung berkisar antara 12.5822.13 ppt (Tabel 1). Nilai tersebut masih berada pada kisaran nilai salinitas yang dapat ditolelir dan menunjang pertumbuhan kepiting bakau. Menurut Setiawan dan Triyanto (2012), kisaran nilai salinitas optimum bagi pertumbuhan kepiting bakau S. serrata berkisar antara 15-25 ppt. Dikatakan juga bahwa pertumbuhan akan menjadi terhambat jika berada pada kisaran salinitas antara $>25-30$ ppt. Sedangkan menurut
La Sara et al. (2006) kisaran nilai salinitas yang dapat ditolelir kepiting bakau $S$. serrata memiliki rentang yang cukup luas yaitu 2-40 ppt. Sementara menurut Ramelan, (1994), nilai salinitas yang sesuai untuk pemeliharaan kepiting bakau berkisar antara 15-25 ppt. Salinitas merupakan parameter lingkungan perairan yang sangat berpengaruh terhadap fase kehidupan kepiting bakau terutama pada saat ganti kulit (moulting) (Gimenez et al., 2003 dalam Winestri et al., 2014).

Hasil pengukuran nilai $\mathrm{pH}$ perairan pada ekosistem mangrove Desa Evu selama penelitian berkisar antara 7.48-7.80 (Tabel 1). Menurut Arifin (2017), perairan dengan nilai $\mathrm{pH}$ 5.5-6.5 dan >8.5 dikategorikan perairan kurang produktif; perairan dengan nilai $\mathrm{pH}$ 6.5-7.5 dikategorikan perairan produktif, sedangkan perairan dengan nilai $\mathrm{pH}$ 7.5-8.5 dikategorikan perairan yang sangat produktif. Perairan demikian sangat cocok bagi pertumbuhan komunitas mangrove, yang merupakan habitat alami utama kepiting bakau. Parameter $\mathrm{pH}$ perairan yang berkisar antara 6,0-8,5 sangat cocok bagi pertumbuhan mangrove (Arifin 2017). Sementara pertumbuhan kepiting bakau sangat baik pada perairan dengan kisaran nilai pH 7,3-8,5 (Robi dan Erlangga, 2014),

Nilai oksigen terlarut (DO) pada perairan ekosistem mangrove Desa Evu selama penelitian berlangsung berkisar antara 1,74-4,35 mg/l (Tabel 1). Menurut Shelley dan Lovatelli (2011), kebutuhan oksigen terlarut bagi pertumbuhan kepiting bakau adalah $>5 \mathrm{mg} / \mathrm{L}$. Meskipun demikian kepiting bakau mampu mentolelir perairan dengan konsentrasi oksigen terlarut yang rendah. Dengan demikian, nilai oksigen terlarut pada ekosistem mangrove Desa Evu masih berada pada kisaran nilai optimum bagi pertumbuhan kepiting bakau.

\section{Fraksi Substrat}

Hasil analisis menunjukan tipe substrat pada ekosistem mangrove Desa Evu terdiri atas pasir kasar (coarse sand), pasir sedang (medium sand), pasir halus (fine sand), pasir sangat halus (very fine sand), lanau kasar (coarse silt), dan lanau sedang (medium silt). Sebagian besar substrat pada stasiun penelitian didominasi oleh pasir halus kecuali stasiun 2 yang didominasi 
DOI: https://doi.org/10.30598/TRITONvol15issue2page58-68

oleh pasir sangat halus (Tabel 2). Fraksi substrat ideal yang disukai kepiting bakau terdiri atas lempung berpasir dan lempung berdebu yang mampu memerangkap air (Siahainenia 2008), sedangkan menurut Setiawan dan Triyanto (2012), habitat yang disukai kepiting bakau bersubstrat sangat halus seperti lempung berdebu. Dikatakan juga bahwa kepiting bakau ditemukan pada habitat yang memiliki tekstur sedang, namun tidak menyukai habitat yang bersubstrat kasar. Substrat berfraksi halus cenderung mudah digali oleh kepiting bakau untuk membuat liang bioturbasi. Proses ini bertujuan untuk agar kepiting bakau dapat bersembunyi dari predator dan membenamkan diri selama air surut. Substrat yang halus pada ekosistem mangrove banyak mengandung serasah dan bahan organik yang dihasilkan dari serasah mangrove. Serasah mangrove selanjutnya akan diurai oleh fungi dan bakteri hingga menjadi detritus. Kelimpahan detritus pada ekosistem mangrove memberikan daya dukung bagi organisme detritofor seperti kelompok Gastropoda (Ellobiodae dan Potomididae) yang merupakan salah satu makanan alami kepiting bakau (Avianto, 2013).

Disisi lain, fraksi substrat halus mendukung pertumbuhan komunitas mangrove sebagai habitat alami utama kepiting bakau. Komunitas mangrove tumbuh dengan baik pada substrat berupa pasir, lumpur atau batu karang, meskipun umumnya ditemukan pada daerah pantai berlumpur, laguna, delta sungai, dan teluk atau estuaria. Areal hutan mangrove umumnya terdiri dari endapan lumpur, kira-kira $75 \%$ pasir halus, sedangkan kebanyakan dari sisanya terdiri dari pasir lempung yang lebih halus lagi. Lumpur melebar pada ketinggian rata-rata pasang surut terendah dan tergenangi air setiap periode pasang (Arifin 2017). Menurut Gita et al. (2015), kerapatan komunitas mangrove yang relatif tinggi dan kondisi fraksi substrat yang relatif masih alami merupakan salah satu penyebab utama kehadiran kepiting bakau, karena menjamin kelangsungan proses biologi reproduksi dan ketersediaan makanan alami. Siahainenia et al. (2016) menyatakan bahwa perairan hutan mangrove sangat cocok untuk kehidupan kepiting bakau, karena menjamin ketersediaan sumber makanan seperti bentos dan serasah.

Tabel 2. Dominasi kategori sedimen pada ekosistem mangrove Desa Evu

\begin{tabular}{cc}
\hline Stasiun & Kategori Sedimen \\
\hline 1 & Pasir halus \\
2 & Pasir sangat halus \\
3 & Pasir halus \\
4 & Pasir halus \\
5 & Pasir halus \\
6 & Pasir halus \\
7 & Pasir halus \\
8 & Pasir halus \\
9 & Pasir halus \\
\hline
\end{tabular}

\section{Kerapatan Spesies Mangrove}

Pada ekosistem mangrove Desa Evu ditemukan 6 (enam) spesies mangrove yaitu: Bruguiera sp., Rhizophora apiculata, Rhizophora mucronata, Ceriops tagal, Sonneratia alba dan Xylocarpus sp. Hasil analisis menunjukan kerapatan dan kerapatan relatif tertinggi diwakili oleh Bruguiera sp., sedangkan terendah oleh Ceriops tagal (Gambar 2). Kerapatan spesies Bruguiera $s p$ berkisar antara 6-29 ind $100 / \mathrm{m}^{2}$ dengan kerapatan relatif berkisar antara 0,06-0,29\%. Kerapatan tertinggi dijumpai pada stasiun 3, sedangkan terendah pada stasiun 7. Kerapatan Rhizophora apiculata berkisar antara 4-28 ind $100 / \mathrm{m}^{2}$ dengan kerapatan relatif berkisar antara 0,04-0,28\%. Kerapatan tertinggi dijumpai pada stasiun 8, sedangkan terendah pada stasiun 3. Kerapatan Rhizophora mucronata berkisar antara 2-11 ind $100 / \mathrm{m}^{2}$ dengan kerapatan relatif berkisar antara $0,02-0,11 \%$. Kerapatan tertinggi dijumpai pada stasiun 3, sedangkan terendah pada stasiun 5 . Kerapatan Xylocarpus sp. berkisar antara 3-54 ind $100 / \mathrm{m}^{2}$ dengan kerapatan relatif berkisar antara 0,03-0,54\%. Kerapatan tertinggi dijumpai pada stasiun 6 , sedangkan terendah pada stasiun 3. Kerapatan Sonneratia alba berkisar antara 17 ind 100/m ${ }^{2}$ dengan kerapatan relatif berkisar antara 0,01-0,07\%. Kerapatan tertinggi dijumpai pada stasiun 7 , sedangkan terendah pada stasiun 8. Sedangkan mangrove spesies Ceriops tagal hanya dijumpai pada stasiun 3 dan 7 dengan kerapatan 1 ind 100/m². 


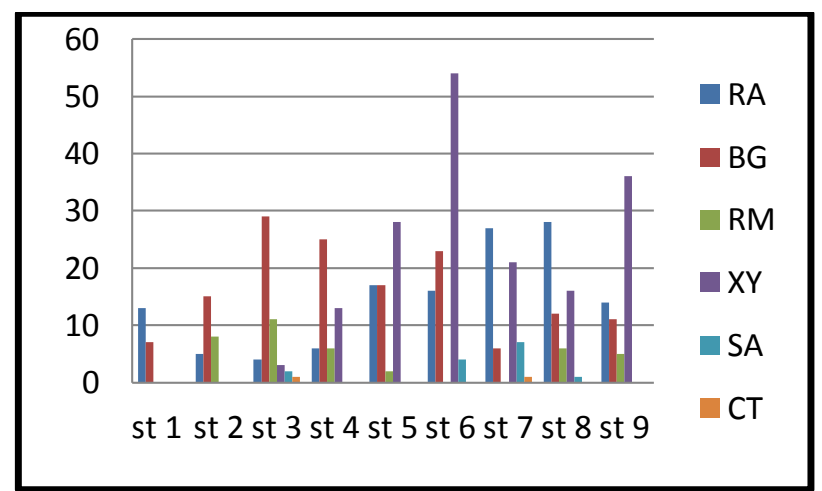

Gambar 2. Kepadatan spesies mangrove di ekosistem mangrove Desa Evu.

\section{Kepadatan Kepiting Bakau (Scylla spp.)}

Hasil identifikasi spesies kepiting bakau yang tertangkap pada ekosistem mangrove Desa Evu sebanyak 2 (dua) spesies kepiting bakau yaitu: Scylla serrata dan S. olivacea. Komposisi jenis kepiting bakau yang sama ditemukan juga oleh Saga (2018) dalam periode penelitian yang berbeda pada bagian lain perairan Hoat Soarbay. Komposisi spesies kepiting bakau pada ekosistem mangrove Desa Evu tergolong rendah dibandingkan dengan ekosistem mangrove di perairan Maluku pada umumnya (Tetelepta \& Makatita, 2012; Siahainenia, 2011; Siahainenia 2008; Siahainenia et al., 2016).

Hasil analisis kepadatan menunjukan nilai kepadatan total kepiting bakau selama periode penelitian Maret-Mei Tahun 2018, berkisar antara 3-21 ind $/ 100 \mathrm{~m}^{2}$. Kepadatan tertinggi dijumpai pada stasiun 3, sedangkan kepadatan terendah dijumpai pada stasiun 7. Kepadatan kepiting bakau antar spesies menunjukan Scylla olivacea memiliki kepadatan tertinggi, berkisar antara $10-28$ ind $/ 100 \mathrm{~m}^{2}$. Sedangkan kepadatan Scylla serrata berkisar antara $4-16 \mathrm{ind} / 100 \mathrm{~m}^{2}$. Kepadatan Scylla olivacea tertinggi dijumpai pada stasiun 3, sedangkan terendah pada stasiun 7, sementara kepadatan Scylla serrata tertinggi dijumpai pada stasiun 1 dan 2, sedangkan terendah pada stasiun 9. Hasil analisis kepadatan antar jenis kelamin menunjukan bahwa individu jantan lebih tinggi dibandingkan betina. Kepadatan individu jantan tertinggi dijumpai pada stasiun 3, sedangkan terendah pada stasiun 7 , sebaliknya kepadatan individu betina tertinggi dijumpai pada stasiun 3 dan 9, sedangkan terendah pada stasiun 5 .

\section{Keterkaitan Karakteristik Habitat dengan Kepadatan Kepiting Bakau}

Hasil analisis PCA menunjukan informasi keterkaitan karakteristik habitat dengan kepadatan kepiting bakau pada bulan Maret, terpusat pada tiga sumbu utama yaitu sumbu F1, F2 dan F3 sebesar 71,72\%. Diagram sumbu F1 dan F2, memberikan gambaran bahwa spesies kepiting bakau Scylla olivacea berdistribusi tinggi pada stasiun 4, 5 dan 9 yang dicirikan oleh kerapatan mangrove jenis Xylocarpus sp. tinggi, dengan nilai $\mathrm{pH}$ tinggi. Sedangkan spesies kepiting bakau Scylla serrata berdistribusi tinggi pada stasiun 3 dan 7, yang dicirikan oleh kerapatan mangrove Sonneratia alba tinggi, serta didominasi oleh substrat dasar pasir kasar, pasir sedang, pasir halus dan lumpur kasar (Gambar 3a). Sementara perpotongan sumbu F1 dan F3 memberikan gambaran bahwa distribusi kepiting bakau spesies Scylla serrata tinggi pada stasiun 1 yang dicirikan oleh nilai $\mathrm{pH}$ yang tinggi (Gambar $3 b$ ).

Spesies Scylla olivacea lebih mendominasi pada jenis mangrove Xylocarpus spp. Noor $d k k$. (2006), menyatakan bahwa jenis Xylocarpus granatum dapat tumbuh di sepanjang pinggiran sungai dan lingkungan payau lainnya yang tidak terlalu asin. Zona ini menempati bagian belakang hutan mangrove, berbatasan dengan hutan darat, dengan tingkat fluktuasi parameter perairan yang rendah. Menurut Avianto et al. (2013), populasi $S$. olivacea banyak ditemukan di bagian belakang hutan mangrove Muara Dua, Segara Anakan, yang bersalinitas rendah dengan ketersedian makanan alami rendah yang rendah. 
DOI: https://doi.org/10.30598/TRITONvol15issue2page58-68

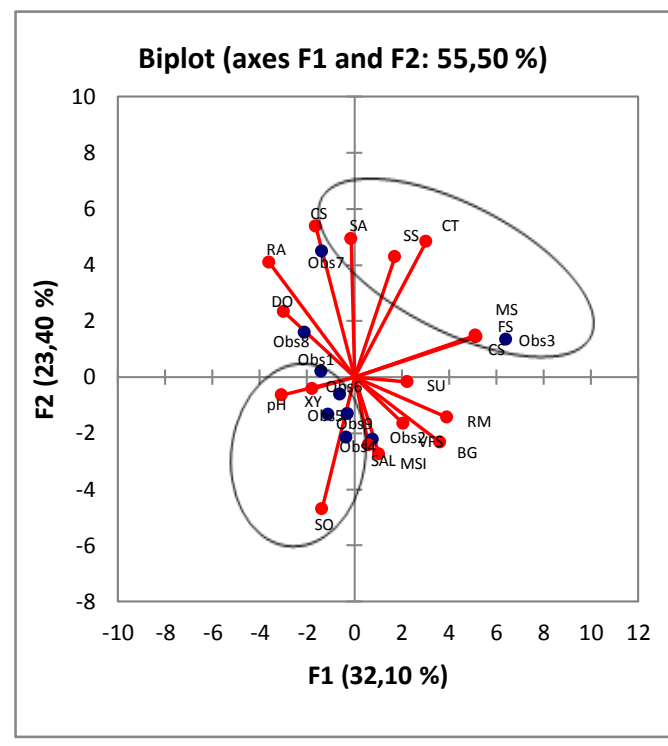

(a)

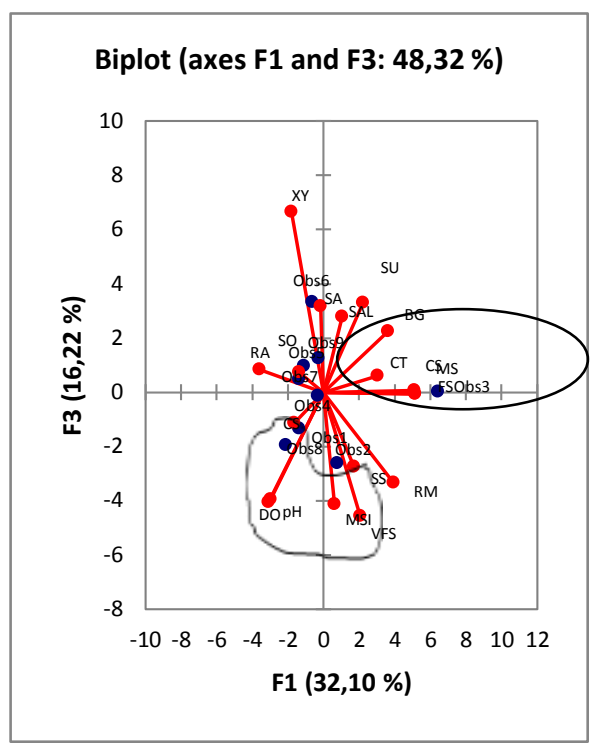

(b)

Gambar 3. Diagram keterkaitan karakteristik habitat dengan kepadatan kepiting bakau selama Maret 2018 pada (a) perpotongan sumbu factorial F1 \& F2; (b) pada perpotongan sumbu factorial F1 \& F3

Gambaran tersebut menunjukan bahwa spesies $S$. olivacea, $S$. paramosain dan $S$. tranqueberica memiliki preferensi pada zona belakang dan tengah hutan mangrove, sedangkan kepiting Scylla serrata lebih mendominasi pada zona depan yang ditumbuhi vegetasi mangrove Sonneratia alba. Hal ini senada dengan hasil penelitian Siahainenia (2008) bahwa Scylla serrata melimpah di zona depan hutan mangrove dan zona laut di perairan Desa Blanakan, Tanjung laut, Mayangan. Secara umum, zona yang paling dekat dengan laut didominasi oleh jenis Avicenia dan Sonneratia alba. La Sara et al. (2014) menyatakan bahwa kelimpahan relatif Scylla serrata cenderung untuk menduduki habitat dengan karakteristik salinitas rendah, kekeruhan tinggi, vegetasi mangrove tebal, substrat berlumpur dan daerah intertidal datar.

Hasil analisis PCA terhadap data yang diperoleh pada bulan April menunjukan bahwa informasi keterkaitan kepiting bakau dengan karakteristik habitat terpusat pada tiga sumbu utama yaitu sumbu F1, F2 dan F3 sebesar $73,87 \%$. Diagram sumbu F1 dan F2 memberikan informasi kepiting bakau jenis Scylla olivacea terdistribusi tinggi pada stasiun
3 yang dicirikan oleh kerapatan mangrove jenis Rhizophora mucronata, Bruguiera sp. yang tinggi dengan dominasi jenis substrat pasir kasar, sedang, dan halus. Kepiting bakau jenis Scylla serrata terdistribusi tinggi pada stasiun 2 dan 3, yang dicirikan oleh kerapatan mangrove Sonneratia alba, Rhizophora mucronata, bruguiera sp yang tinggi, dengan substrat dasar pasir kasar, pasir sedang, pasir halus, pasir sangat halus dan lumpur (Gambar 4a). Sementara perpotongan sumbu F1 dan F3 memberikan informasi tentang distribusi kepiting bakau jenis Scylla olivacea pada stasiun 7 yang dicirikan kerapatan rhizophora apiculata, ceriops tagal rendah, dengan substrat dasar pasir kasar, pasir sedang, dan pasir halus yang tinggi (Gambar 4b). Pada bulan April, kepiting Scylla olivacea lebih mendominasi pada zona mangrove genus Bruguiera, karena zona ini merupakan zona belakang hutan mangrove dengan tingkat fluktuasi parameter perairan yang rendah. Sedangkan kepiting Scylla serrata lebih mendominasi pada zona mangrove genus Rhizophora karena pada zona ini merupakan zona depan hutan mangrove, serta mangrove genus Bruguiera yang merupakan zona belakang hutan mangrove. 


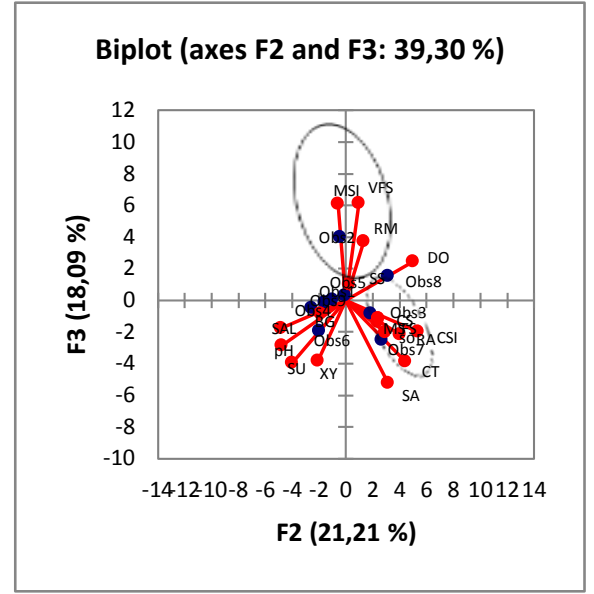

(a)

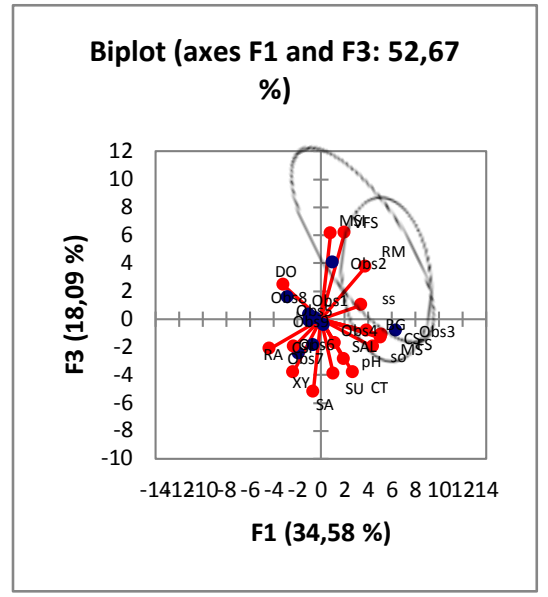

(b)

Gambar 4. Diagram keterkaitan karakteristik habitat dengan kepadatan kepiting bakau selama April 2018 pada (a) perpotongan sumbu factorial F1 \& F2; (b) pada perpotongan sumbu factorial F1 \& F3

Kepiting Scylla serrata memiliki preferensi pada zona depan mangrove yang berhadapan langsung dengan perairan laut, serta mampu hidup pada zona yang memiliki kondisi parameter fisik kimia lingkungan cenderung tinggi maupun rendah (Siahainenia, 2010). Menurut Saga (2018) pada seluruh lokasi stasiun di mangrove dapat ditemukan kepiting Scylla olivacea dan Scylla serrata. Hal ini berkaitan dengan tingkat adaptasi terhadap kualitas perairan yang dapat ditorerir. Demikian kepiting Scylla olivacea dan Scylla serrata memiliki zona preferensi untuk dijadikan tempat berlindung dari predator.
Hasil analisis PCA terhadap data yang diperoleh selama bulan Mei menunjukan bahwa informasi keterkaitan kepiting bakau karakteristik habitat terpusat pada tiga sumbu utama yaitu sumbu F1, F2 dan F3 sebesar $74,50 \%$. Diagram sumbu F1 dan F2 memberikan informasi bahwa kepiting bakau jenis Scylla olivacea berdistribusi tinggi pada stasiun 4 dan 9 yang dicirikan oleh kerapatan mangrove jenis rhizophora mucronata dan salinitas tinggi, serta distribusi Scylla serrata yang tinggi pada stasiun 2, yang dicirikan oleh substrat dasar pasir sangat halus (Gambar 5a).

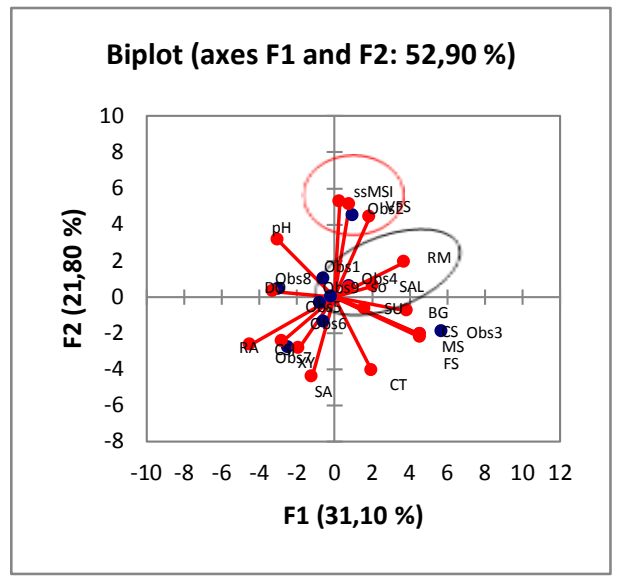

(a)

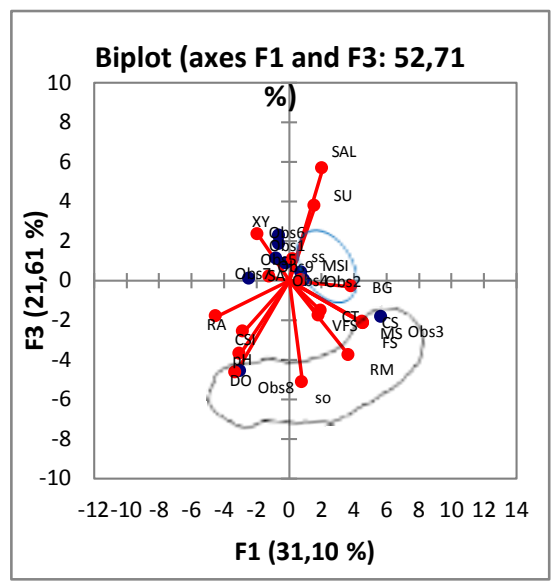

(b)

Gambar 5. Diagram keterkaitan karakteristik habitat dengan kepadatan kepiting bakau selama Mei 2018 pada (a) perpotongan sumbu factorial F1 \& F2; (b) pada perpotongan sumbu factorial F1 \& F3 
Sementara perpotongan sumbu F1 dan F3 memberikan informasi tentang distribusi kepiting bakau jenis Scylla olivacea pada stasiun 3 dan 8 yang dicirikan dengan kerapatan Rhizophora apiculate. Pada kedua stasiun ini memiliki karakteiristik substrat dasar berupa pasir kasar, pasir sedang, dan pasir halus yang tinggi (Gambar 5b). Selama bulan Mei, Scylla olivacea lebih mendominasi pada zona mangrove Rhizophora. sedangkan Scylla serrata mendominasi zona bersubstrat pasir halus, lumpur kasar dan lumpur sedang. Tekstur substrat dasar yang baik bagi kehidupan kepiting bakau terdiri dari lempung berpasir (sandy loam) atau lempung berdebu (silty loam) dan tidak bocor yang berfungsi untuk menahan air (Setiawan dan Triyanto, 2012). Tekstur substrat yang sangat halus seperti lempung berdebu disukai oleh kepiting bakau sebagai habitatnya (Tahmid $d k k ., 2015$ ). Selain itu kepiting bakau juga ditemukan pada habitat yang memiliki tekstur sedang, namun tidak menyukai habitat yang bersubstrat kasar. Substrat lempung berdebu tersebut, memudahkan proses penggalian oleh kepiting bakau untuk membuat liang atau lubang yang digunakan untuk membenamkan diri, bersembunyi, mempertahankan diri agar tetap dingin selama air surut dan melindungi diri dari predator. Tahmid dkk., (2015) menyatakan bahwa substrat yang halus pada ekosistem mangrove banyak mengandung serasah dan bahan organik yang dihasilkan dari daun mangrove yang jatuh ke lumpur sekitar pohon mangrove yang selanjutnya akan terdekomposisi oleh bakteri, sehingga banyak ditemukan makanan bagi organisme tertentu seperti kelompok Gastropoda (Ellobiodae dan Potomididae) yang diketahui merupakan salah satu makanan alami kepiting bakau (Avianto, 2013).

\section{KESIMPULAN}

Kesimpulan dari hasil penelitian ini yaitu kepiting bakau jenis Scylla olivacea terdistribusi tinggi pada zona yang ditumbuhi mangrove Xylocarpus sp., Rhizophora mucronata dan

DOI: https://doi.org/10.30598/TRITONvol15issue2page58-68

Bruguiera sp. dengan nilai $\mathrm{pH}$, DO, dan salinitas yang tinggi; serta fraksi substrat pasir halus dan pasir kasar. Sedangkan S. serrata terdistribusi tinggi pada zona yang ditumbuhi mangrove Sonneratia alba, Rhizophora mucronata dan Bruguiera sp., serta bersubstrat dasar pasir halus dan lumpur

\section{DAFTAR PUSTAKA}

Arifin, A. 2017. Struktur Vegetasi Mangrove Berdasarkan Substrat di Pantai Mara Bombang Kecamatan Suppa Kabupaten Pinrang. Skripsi. Universitas Hasanuddin. Badan Karantina Ikan, Pengendalian Mutu dan Keamanan Hasil Perikanan Kementerian Kelautan dan Perikanan.

Avianto, I., Sulistiono, I. Setyobudiandi. 2013. Karakteristik Habitat dan Potensi Kepiting Bakau (Scylla serrata, S. transquaberica, dan S. olivacea) di Hutan Mangrove Cibako, Sancang Kabupaten Garut Jawa Barat. J. Ilmu Perikanan dan Sumberdaya Perairan. Aquasains, 2(1):97-106.

Behera, B.C., R.R. Mishra, J.K. Patra, S.K. Dutta, H.N. Thatoi. 2014. Physico Chemical Properties of Water Sample Collected from Mangrove Ecosystem of Mahanadi River Delta, Odisha, India. American J. of Marine Science, 2(1):19-24.

Cholik, F. 1999. Review of Mud Crab Culture Research in Indonesia. In Mud Crab Aquaculture and Biology. ACIAR Proceedings no. 78. Canberra. Australia, 1420pp.

Gita, R. S. D., Sudarmadji., Waluyo, J. 2015. Pengaruh Faktor Abiotik Terhadap Keanekaragaman dan Kelimpahan Kepiting Bakau (Scylla spp.) di Hutan mangrove Blok Bedul Taman Nasioanal Alas Purwo. Jurnal Ilmu Dasar Vol. 16 No. 2: 63 - 68

Khouw, A. S. 2016. Metode dan Analisa Kuantitatif Dalam Bioekologi Laut. Penerbit Alfabeta. Bandung

Larosa, R., B. Hendrarto, M. Nitisupardjo. 2013. Identifikasi Sumberdaya Kepiting Bakau $($ Scylla sp.) yang Didaratkan di TPI Kabupaten Tapanuli Tengah. J. of Management of Aquatic Resources, 2(3):180189

La Sara, J.A. Ingles, R.O. Aguilar, L.V. Laureta, R.B. Baldevarona, S. Watanabe. 2006. 
Abundance and Distribution Patterns of Scylla spp. Larvae in The Lawele Bay, Southeast Sulawesi, Indonesia. Asian Fisheries Sciences, 19:331-347.

Mawarni, M., R. Irnawati, A. susanto. 2014. Sebaran Daerah Penangkapan Kepiting Bakau (Scylla sp.) di Perairan Karangantu Serang Banten. $J$. Ilmu Pertanian dan Perikanan, 3(1):47-54.

Robi, M., \& Erlangga. 2014. Pengaruh Ablasi Mata Terhadap Kecepatan Kematangan Gonad Kepiting Bakau (Sylla serrata) Betina. Aquatic Sciences Journal. Acta Aquatica 1:1. 14-19.

Saga, M, M,I.A. 2018. Hubungan mangrove Genus Brugera dan Rhizophora Terhadap Keberadaan Kepiting Sylla serrata dan Scylla olivacea Di Hoat Soarbay, Kei Kecil, Maluku Tenggara. Skripsi. Departemen Ilmu dan Teknologi Kelautan Fakultas Perikanan dan Ilmu KelautanInstitut Pertanian. Bogor.

Shalley, C. and A. Lovatelli. 2011. Mud crab Aquaculture a Practical Manual. FAO Fisheries and Aquaculture Technical Paper. $78 \mathrm{p}$.

Siahainenia, L. 2008. Apek Bioekologi Kepitinf Bakau (Scylla spp.) Pada Ekosistem Mangrove Kabupaten Subang Jawa Barat. Disertasi. Sekolah Pascasarjana IPB. Bogor.

Siahainenia, L. 2010. Kajian Potensi Reproduksi Dalam Upaya Pengelolaan Kepiting Bakau (Scylla spp.) pada Ekosistem Mangrove Passo Teluk Ambon Dalam. Prosiding Konas VII. Departemen Kelautan dan Perikanan RI. Jakarta.

Siahainenia, L. 2011. Potency and Spacial Distribution of Mud Crabs at Mangrove Ecosystem in Inner Ambon Bay. Proceeding International Seminar Role of Postgraduate Study in Sustainability Development of Archipelagic Communities. Postgraduate Forum Ambon.

Siahainenia, L. 2014. Evaluasi Potensi Sumberdaya Kepiting Bakau (Scylla spp.) Pada Ekosistem Mangrove Teluk Pelita Jaya Kabupaten Seram
Bagian Barat Maluku Tengah. Prosiding Seminar Nasional Tahunan XIII Hasil Penelitian Perikanan dan Kelautan. Departeman Perikanan Fakultas Pertanian UGM Jilid 2. Hal 1-9.

Siahainenia, L. Y. Natan, A.S. Khouw, J.A. Pattikawa. 2016. Size Distribution, Growth Pattern and Condition Factor of Mangrove Crab Scylla serrata in The Coastal Waters of Western Seram, Maluku, Indonesia. International Journal of Fisheries and Aquatic Studies 4(2): 291-296

Siahainenia, L. 2016. Potensi Kepiting Bakau Scylla spp. di Ekosistem Mangrove Passo Teluk Ambon. Prosiding Seminar Nasional Tahunan XIII Hasil Penelitian Perikanan dan Kelautan. Departeman Perikanan Fakultas Pertanian UGM Jilid 2. Hal 11-18.

Tahmid, M., Fahrudin, A., Wardiatno, Yusli. 2015. Kajian Struktur Ukuran Dan Parameter Populasi Kepiting Bakau (Scylla serrata) di Ekosistem Mangrove Teluk Bintan, Kepulauan Riau. Jurnal Biologi Tropis, Vol. 15, No. 2. pp. 93-106.

Tetelepta, J. M \& M. Makatita. 2012. An Approach to The Management of Mud Crab Scylla serrata Through The Reproductive Status of Mud Crab and Socio Economy and institutional Aspects of The Fisherman At Pelita Jaya, West Seram District. Triton: Jurnal Manajemen Sumberdaya Perairan $8(1): 1-11$

Triyanto, N.I., I. wijaya, T. Yuniarti, Widianti, F. Sutrisno. F. Setiawan, S. Lestari. 2013. Peranan Ekologis Hutan Mangrove Dalam Menunjang Produksi Kepiting Perikanan Bakau (Scylla serrata) di Kabupaten Berau. Prosiding Pertemuan Ilmiah Tahunan MLI I. Hal:275-284

Yamin, M., \& Sulaeman. 2011. Pengangkutan Krablet Kepiting Bakau Sistem Kering. Prosiding Forum Inovasi Teknologi Akuakultur. Hal:1297-1302. 